\title{
Experimental Aerodynamic Comparison of Active Camber Morphing and Trailing Edge Flaps
}

\author{
Andres E. Rivero* and Stephane Fournier ${ }^{\dagger}$ \\ Bristol Composites Institute (ACCIS), University of Bristol, Bristol, BS8 ITR, UK \\ Marinos Manolesos \\ College of Engineering, Swansea University, Bay Campus, Swansea, SA1 8EN, UK \\ Jonathan E. Cooper ${ }^{\S}$ \\ Department of Aerospace Engineering, University of Bristol, Bristol, BS8 ITR, UK \\ Benjamin K.S. Woods ${ }^{\mathrm{I}}$ \\ Bristol Composites Institute, University of Bristol, Bristol, BS8 1TR, UK
}

Unlike hinged flaps (e.g. ailerons, elevator and rudder), camber morphing devices vary camber distribution in a smooth and continuous way, resulting in aerodynamic efficiency improvements due to the absence sharp changes in airfoil camber. One such camber morphing concept, the Fish Bone Active Camber (FishBAC) device, has shown significant aerodynamic benefits when compared to a flap. In this work, a quasi-2D wind tunnel test was performed to investigate the aerodynamic performance of a FishBAC device and compare it to a trailing edge plain flap. A combination of quasi-steady force balance and wake rake pressure measurements were used to determine aerodynamic force coefficients. These measurements are complemented by a flow visualization study performed using Particle Image Velocimetry, allowing for comparison of the near field wakes in terms of size and vortical structure. Additionally, displacement measurements were performed on the FishBAC to track deformed shapes under aerodynamic loads. Results show that the FishBAC achieves greater than a 50\% improvement in lift-to-drag ratio for moderate to high lift coefficients where the device is significantly deflected, and at least $16 \%$ higher lift-to-drag ratio at all lift coefficients, even when the device deflections are low.

\section{Nomenclature}

$\alpha_{u} \quad=\quad$ uncorrected angle of attack

$\alpha=$ corrected angle of attack

\footnotetext{
*Research Associate, Bristol Composites Institute, Department of Aerospace Engineering, AIAA Member.

${ }^{\dagger}$ Senior Research Associate, Bristol Composites Institute (ACCIS)

ॠSenior Lecturer in Aerospace Engineering, College of Engineering, Swansea University.

${ }^{\S}$ RAEng Airbus Sir George White Professor, Department of Aerospace Engineering, AIAA Fellow.

"I Senior Lecturer in Aerospace Structures, Bristol Composites Institute, AIAA Member.

Presented at the 2020 AIAA SciTech Forum, Orlando, Florida 6-10 January 2020 (Manuscript No. AIAA 2020-1300)
} 


\begin{tabular}{|c|c|c|}
\hline$b$ & $=$ & span \\
\hline$c$ & $=$ & chord length \\
\hline$C_{D}$ & $=$ & drag coefficient \\
\hline$C_{d_{0}}$ & $=$ & profile drag coefficient \\
\hline$C_{L}$ & $=$ & lift coefficient \\
\hline$D$ & $=$ & drag force \\
\hline$\delta$ & $=$ & actuation input angle \\
\hline$\epsilon$ & $=$ & actuation efficiency factor \\
\hline$F_{i_{1}}$ & $=$ & bottom balance measured force \\
\hline$F_{i_{2}}$ & $=$ & top balance measured force \\
\hline$H$ & $=$ & total pressure \\
\hline$I$ & $=$ & current \\
\hline$k_{t}$ & $=$ & torque constant \\
\hline$L$ & $=$ & lift force \\
\hline$p$ & $=$ & static pressure \\
\hline$q$ & $=$ & dynamic pressure \\
\hline$\rho$ & $=$ & air density \\
\hline$R e$ & $=$ & corrected Reynolds number \\
\hline$S$ & $=$ & wing planform area \\
\hline$T$ & $=$ & torque \\
\hline$\overline{u^{\prime} u^{\prime}}, \overline{v^{\prime} v^{\prime}}$ & $=$ & velocity fluctuations \\
\hline$V_{\infty}$ & $=$ & freestream flow speed \\
\hline
\end{tabular}

\section{Introduction}

Modern fixed-wing aircraft are maneuvered by control surfaces that vary airfoil camber. These variations in camber create time varying forces and moments that result in changes in flight path. Traditionally, these changes in camber are achieved by actuating a series of hinged flaps located at the trailing edge of the airfoil (e.g. ailerons, elevator and rudder). Although simple, effective, and ubiquitous, the sudden and discontinuous camber change created by flaps causes a significant increase in drag. Also, because flaps are hinged, a structural gap must exist between the start of the flap and the rigid wing so that it can rotate about its pivot point. These gaps are an additional source of drag and noise.

An alternative to hinged flaps is to change camber in a smooth and continuous way, without sharp surface discontinuities, and also without the chordwise gap present at the start of the flap. Camber morphing devices are being introduced to create these smooth and continuous changes in camber, and if designed correctly, they can produce the same changes in lift coefficient that hinged flaps achieve, but with a much lower drag penalty [1]. Consequently, they have been a subject of a significant amount of research in recent years, as reviewed by Barbarino et al. [2]. With the reduction of the inherent drag penalty of hinged flaps comes a promising set of opportunities to use camber morphing beyond control purposes-e.g. to continuously optimize performance throughout flight. These improvements in performance can be both in a two-dimensional sense, by optimizing the lift-to-drag ratio of the airfoil at any flight stage, and in a three-dimensional sense through spanwise variations of camber to optimize spanwise lift distribution and reduce induced drag [3]. 
Although not a new concept—indeed camber morphing mechanisms date from as early as 1920 [4-6] - interest in these concepts has grown significantly in the past two decades due to advancements in smart materials, lightweight composite structures, and sophisticated new analysis and design tools [7,-12]. Of particular note in previous camber morphing literature are the F-111 Mission Adaptive Wing, based on a series of several hinged flaps [13]; the Flexys Flexfoil, capable of achieving $\pm 10^{\circ}$ of out-of-plane deflection; the DARPA Smart Wing, which combined a plate structure with a honeycomb core [14]; the DLR Belt-Rib concept [15] and the Fish Bone Active Camber (FishBAC) morphing trailing edge device, which is subject of study of this wind tunnel experiment (Fig. 1) [16].

However, it can be observed in the literature that most of the research efforts have focused on the structural design and analysis. While numerical and experimental studies on camber morphing aerodynamic performance are fairly common, direct aerodynamic comparisons between these devices and traditional hinged control surfaces_-especially wind tunnel comparisons_-are scarce. Early studies in late 1980s and early 1990s introduced preliminary results that show, quantitatively, an improvement in aerodynamic efficiency of up to $9 \%$ when variable camber morphing is used. However, these results are not related to a specific morphing concept [15, 17, 18]. Another preliminary study based on wind tunnel data even predicts a 3 to 6 percent reduction in fuel consumption, for a long/medium range civilian aircraft [1].

Daynes and Weaver [19] carried out a wind tunnel test of a compliant trailing edge, where an increase of lift coefficient of $\Delta C_{L} \approx 0.5$ can be observed when actuating the morphing device between $\pm 10^{\circ}$ deflection. No flap comparison was performed in this study. Bilgen et al. [20] also conducted a 2D wind tunnel test comparison of a flapped airfoil versus a Macro-Fiber-Composite (MFC) actuated variable camber wing and results showed an increase in lift-to-drag ratio of 10\%-50\% when camber morphing is used. Ai et al. [21] also presented wind tunnel tests results - which were compared to Computational Fluid (CFD) studies-of several camber morphing cases versus a hinged flap. Although they showed improvements in aerodynamic efficiency, these improvements were limited to low angles of attack, achieving an increase in $L / D$ of about $9 \%$ at zero-degree angle of attack. Moreover, Yokozeki et al. [22] presented wind tunnel test results for a corrugated camber morphing device. These results do not show significant improvement in aerodynamic efficiency when compared to a flap. However, it is important to note that this particular morphing device presents a smooth skin on the top surface only, leaving the core corrugations exposed on the bottom surface, which likely adds drag to the camber morphing device.

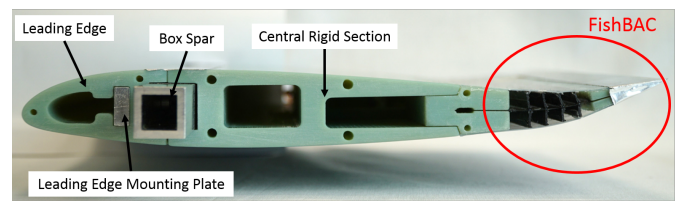

Fig. 1 FishBAC camber morphing trailing edge device attached to a NACA 23012 wing tunnel model. 
The subject of this study, the Fish Bone Active Camber (FishBAC) concept, was originally introduced by Woods and Friswell [16]. The FishBAC is a morphing trailing edge device that is capable of generating large, smooth and continuous changes in camber. It benefits from an anisotropic design, being significantly more compliant chordwise than spanwise. This anisotropic design focuses the compliance in the camber direction reducing the actuation energy requirements, while maintaining spanwise bending rigidity. The structure of the FishBAC consists of a central bending plate (the spine), a series of spanwise stringers branching off of the spine which support an elastomeric pre-stressed skin, and a series of antagonistic tendons that create bending moments about the trailing edge of the bending spine.

A preliminary wind tunnel test of the FishBAC [23] showed a potential improvement in lift-to-drag ratio between 20 and 25 percent, compared to a 25\%-chord trailing edge flap. It also showed a FishBAC lift control authority of $\Delta C_{L} \approx 0.72$. However, this test had significant 3D aerodynamic effects due to the nature of their wind tunnel setup. This means that while the test was still a direct comparison between flaps and FishBAC, as both devices had the same flow environment, it was not indicative of what could be achieved in more two-dimensional flow regimes. Additionally, the FishBAC concept has evolved significantly since that initial wind tunnel test: the morphing section is now smaller, spanning between $0.75 c$ and $0.9 c$ of chord, instead of between $0.35 c$ and $0.85 c$. This more localized FishBAC configuration has significantly improved structural and aerodynamic properties for both the device and the wing it sits on. Previous studies showed that a 25\%-chord FishBAC presents lower drag at high lift coefficients (compared to having larger morphing sections, e.g. 50\%- or 75\%-chord). Also, having a smaller morphing device is useful from a structural point-of-view, as a smaller portion of the baseline rigid wing is morphed. Therefore, the global stiffness and strength of the wing may be higher and thus, more structurally robust [24]. In summary, additional wind tunnel tests are warranted—especially if more sophisticated measurement techniques can be brought to bear to better interrogate the physical sources of improved performance.

The objective of this wind tunnel experiment is therefore to more comprehensively assess the aerodynamic performance of the FishBAC, experimentally, using an improved design of FishBAC installed into a higher aspect ratio wing and tested in a closed return and closed test section tunnel for improved flow quality. Furthermore, the instrumentation used to quantify the performance is significantly improved from the preliminary wind tunnel test by Woods et al. [23], as force balances and a pressure-based wake rake are used for more reliable measurements. Also, this experiment addresses the lack of flow visualization and structural behavior studies of camber morphing devices in the literature by performing flow visualization and structural displacement measurements using Particle Image Velocimetry (PIV) and a stereo videogauge point-tracking system (VG), respectively. These measurements will be used to enhance the understanding of the benefits of camber morphing by studying the changes in wake patterns and comparing them to the wake of a hinged flap, while also providing insight into the coupled aeroelastic response of the system that is useful for design improvements and for future validation of fluid-structure interaction (FSI) analysis. 


\section{Methodology}

This section introduces the wind tunnel testing methodology, including details of the tunnel itself, the equipment and instrumentation used, and the configurations tested.

\section{A. Wind Tunnel \& Equipment}

The Swansea University closed return low speed wind tunnel, with a $1.5 \mathrm{~m}$ wide $\times 1 \mathrm{~m}$ tall closed test section, was used for this experiment. This tunnel has a maximum freestream velocity of $50 \mathrm{~m} / \mathrm{s}$, and flow characterization studies have measured turbulence intensity, velocity uniformity and flow angularity values of $0.175 \%, 0.04 \%$ and $\pm 0.1^{\circ}$, respectively. A turntable with movable range of $\pm 90^{\circ}$ and accuracy of $\pm 0.05^{\circ}$ controls the angle of attack of the wing. Moreover, the wing was mounted vertically, fully spanning the test section and was attached to two strain-gauge based AMTI MC12-1000 six-axis force balances, one on each end. Equipped with a temperature control system, a target temperature of $20^{\circ} \mathrm{C}$ is maintained within $\pm 2^{\circ} \mathrm{C}$ accuracy. A closed loop feedback system controls wind speed using real time velocity calculations based on a precision differential pressure sensor with a range of $\pm 2500 \mathrm{~Pa}$ [25], which measures the pressure difference at the contraction section upstream of the test section.

\section{Pressure Wake Rake}

A pressure-based wake rake for wake survey has recently been added to the Swansea University Low-Speed Wind Tunnel. The rake consists of 60 total pressure and 3 static pressure tubes mounted 4.5 chords downstream of the wing trailing edge. This mounting distance allows for pressure recovery in the wake. The total and static pressure tubes, respectively, are aligned in the thicknesswise direction (which is horizontal with a vertical wing mounting), with a modest spanwise offset between the total and static pressure tubes to avoid interference. A Scanivalve MPS4264 miniature pressure scanner is connected to the rake tubes and measures the total pressure at each tube, individually. The total pressure tubes have variable thicknesswise spacing of between $3.9 \mathrm{~mm}$ (at center) and $15.9 \mathrm{~mm}$ (toward the ends), covering a total thicknesswise width of $500 \mathrm{~mm}$. This variable spacing allows performing more pressure measurements in the wake region than outside the wake, improving the overall accuracy of the drag measurements.

\section{Image Measurements}

This section introduces the equipment used for both Particle Image Velocimetry (PIV) and displacement measurements via stereo point tracking.

\section{Particle Image Velocimetry (PIV)}

An external LaVision ${ }^{\circledR}$ Particle Image Velocimetry system is used for aerodynamic image measurements, controlled with the DaVis 10 software platform. An sCMOS 5.5-megapixel double shutter camera is aligned with the trailing edge of the wing and is used to measure the wake of both FishBAC and flap in a quasi-static flow condition. The camera has 
an exposure time range between $15 \mu \mathrm{s}$ and $100 \mathrm{~ms}$ and a frame rate of $50 \mathrm{fps}$. A particle generator was used to generate seeding particles with an average diameter of $1 \mu \mathrm{m}$. Lastly, a dual cavity, double pulse $200 \mathrm{~mJ}$ Nd:YAG green laser with a wavelength of $532 \mathrm{~nm}$ was used to illuminate the measuring plane. Fig. 2 shows a schematic of the PIV setup.

\section{Stereo Point Tracking System}

An Imetrum ${ }^{R}$ 3D Precision Displacement Tracker was used to track out-of-plane displacements. The system consists of two 5 -megapixel cameras in a stereo configuration, recording at a rate of $117 \mathrm{~Hz}$. These two cameras are mounted to a 3D measurement head (ICA-3D-0500-03) - a pre-calibrated frame where both cameras are installed at a fixed angle and distance from each other. Since the cameras' focus, position and angle cannot be altered from their default configuration, no further calibration is required. For the selected 3D measurement head, a measurement area of $600 \mathrm{~mm} \times 600 \mathrm{~mm}$, with a $14 \mu \mathrm{m}$ accuracy can be achieved [26]. In this experiment, an accuracy of $48.5 \mu \mathrm{m}$ was achieved. A series of $5 \mathrm{~mm}$ diameter bulls-eye stickers were used as target points. Fig. 2 shows a schematic of the videogauge setup.

\section{B. Wind Tunnel Wing Model}

A quasi-two-dimensiona * wind tunnel model of a NACA 23012 airfoil fitted with a FishBAC morphing device was designed and manufactured for this work. The wing spans the 1-meter height of the tunnel test section and has a chord length of $270 \mathrm{~mm}$. The wing has two main sections: a front rigid module that starts at the leading edge and ends at $75 \%$ of the chord, and a trailing edge section. The front rigid segment is composed of 3D-printed plastic leading edge and center parts that are bolted to an aluminum (6082T alloy) box spar located at the quarter chord. Three interchangeable trailing edge 'cartridges' were created for testing the three different configurations: the baseline NACA 23012, a 25\% trailing edge flap version, and a $25 \%$ trailing edge FishBAC. These cartridges bolt to the center wing section and can be easily slid out to change the wing configuration. The aluminum spar is clamped in one end to the bottom force balance, which rotates with the turntable. Since the top force balance does not rotate, the other side of the spar connects to it via a spherical bearing, allowing changes in angle of attack and minimizing the bending moments transferred to the upper force balance. Details of the construction of the three configurations follow:

1) Rigid NACA 23012 Airfoil (Fig. 3a)

A 3D printed rigid NACA 23012 trailing edge section is tested to obtain a baseline data set of lift and drag properties of this airfoil section when no changes of camber occur. Results from the baseline airfoil will be used to validate the tunnel instrumentation, before being used as a reference against which the flap and FishBAC will be compared.

2) Trailing Edge Flap (Fig. 3p)

\footnotetext{
*In this context, quasi-two-dimensional is used to acknowledge the existence of 3D aerodynamic effects in this two-dimensional setup. Since the FishBAC is actuated at two discrete spanwise points, its deflection is not uniform along the span. Therefore, spanwise variations in aerodynamic loads exist. However, the wing still spans the test section as in standard 2D wind tunnel tests.
} 
A 3D-printed hinged flap of the same chord dimension of the FishBAC is tested to directly compare the two approaches. The flap is mounted to a steel shaft and actuated by two KST X10 high voltage servos that are connected to the flap by a system of external control horns and linkage bars. The flap is a plain flap, with no aerodynamic overhang (which is sometimes used to reduce hinge moments at the expense of added drag) and with the minimal realizable gap between the flap and the rigid wing section, on the order of $2 \mathrm{~mm}$. The front of the flap has a semicircle shape with an $8.5 \mathrm{~mm}$ radius, and is centered at $50 \%$ thickness at the chordwise location $x / c=0.75$. The $2 \mathrm{~mm}$ gap between the front of the flap and the rest of the airfoil was the smallest achievable given the materials used, the manufacturing tolerances, and the desire to avoid interference or contact when under load.

3) Camber Morphing: FishBAC (Fig. 35)

The central bending spine of the FishBAC was manufactured using three plies of 8552/IM7 carbon fiber prepreg, with a total cured thickness of $0.39 \mathrm{~mm}$. A stacking sequence of $[90 / 0 / 90]_{T}$ (with 90 degrees being the spanwise direction) was used to provide additional material anisotropy to complement the geometric anisotropy of the FishBAC. A total of eight stringers (four on each surface) were 3D-printed along with a solid trailing edge insert and then bonded to the spine using a cyanoacrylate adhesive. Moreover, the FishBAC is actuated at two spanwise points located between $[0.07 b, 0.095 b]$ and $[0.93 b, 0.955 b]$, respectively. Each actuation point is fitted with two KST X10 high voltage servo actuators with a maximum output torque of $1.05 \mathrm{Nm}$ each. The torque is transmitted from the actuators to the composite spine using an antagonistic tendon system. A $25 \mathrm{~mm}$ wide aramid (Kevlar) fabric tape was used for the tendons, which run through slots in the stringers and over the trailing edge insert before being stitched and bonded to the trailing edge of the carbon spine. Transverse deflections of up to $\pm 10 \%$ chord can be achieved when actuated in absence of aerodynamic loads. It is worth noting here that the use of two fairly spaced out actuation points along the span will lead to variations in camber along the span due to elastic washout, introducing 3D effects to the wind tunnel test. In this particular specimen, the use of printed plastic stringers instead of composite ones significantly reduces the spanwise rigidity, increasing the amount of elastic washout.

\section{Aerodynamic Predictions: XFOIL}

To compare against the wind tunnel results for the baseline airfoil, two-dimensional numerical predictions of the aerodynamic performance of the baseline airfoil were obtained using the XFOIL panel method software [27]. Reynolds and Mach number were set to 540,000 and 0.087 respectively to match the experimental values. Additionally, to roughly match the turbulence intensity of the Swansea University Wind Tunnel, a value of $N_{\text {crit }}$ equal to 5 was used for all XFOIL estimates. 


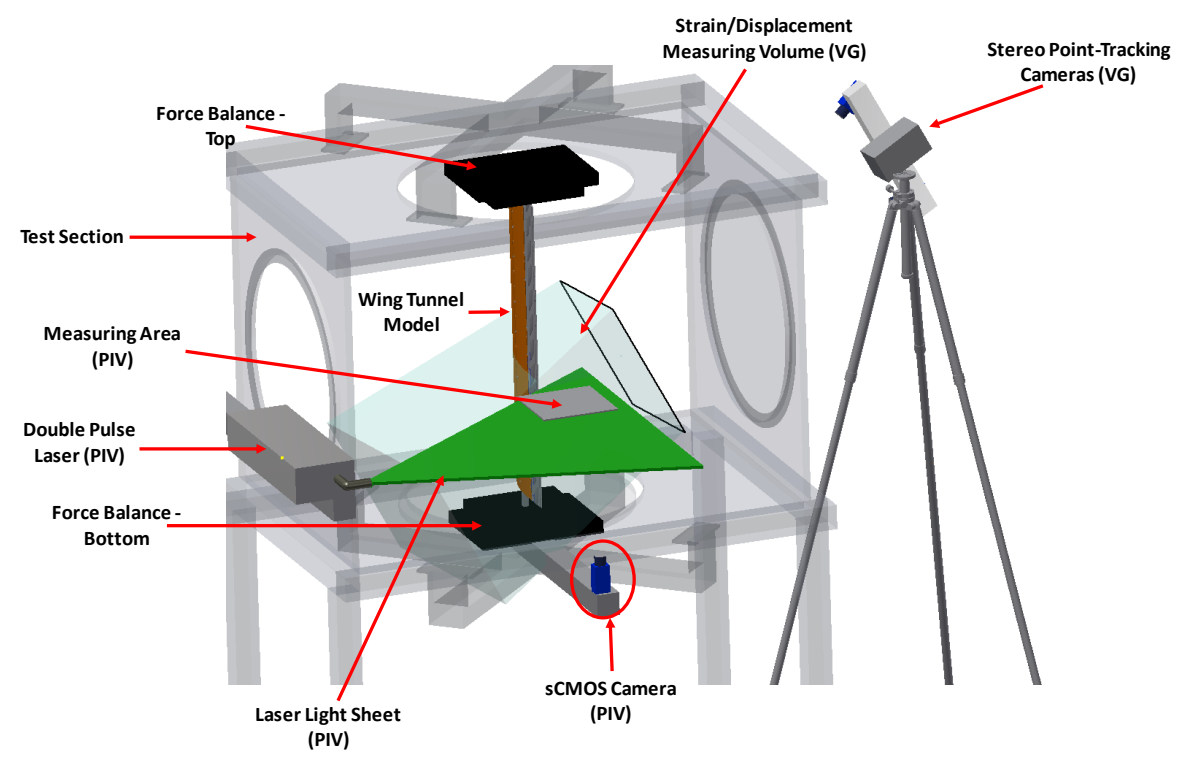

Fig. 2 Schematic of the wind tunnel test setup, including wind tunnel wing model, force balances and PIV and VG equipment

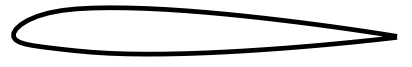

(a) Baseline NACA 23012

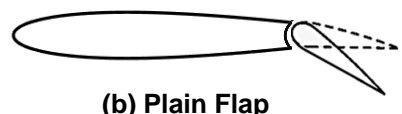

(b) Plain Flap

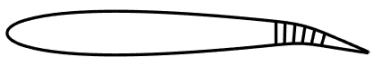

(c) Camber Morphing: FishBAC

Fig. 3 The three configurations that were tested: (a) Baseline, (b) Plain Flap and (c) FishBAC.

\section{Test Cases}

For the three wing configurations, experiments were run at a freestream velocity of $30 \mathrm{~m} / \mathrm{s}$, which corresponding to a Reynolds number of about 540,000. The angle of attack was varied from $\alpha=-5^{\circ}$ to $\alpha=+14^{\circ}$, in increments of $\alpha=1^{\circ}$. Force balance data were recorded for $30 \mathrm{~s}$ for each test condition at a sampling rate of $300 \mathrm{~Hz}$, and then time averaged to give quasi-steady results. The same data recording process was followed for wake survey, which was synchronized with balance measurements using a sampling time and rate of $20 \mathrm{~s}$ and $10 \mathrm{~Hz}$, respectively. Two types of wake rake measurements were performed: $(i)$ actuation and angle of attack sweeps with the wake rake at a fixed spanwise location, and (ii) spanwise wake rake location sweeps at fixed angle of attack and actuation input. These two types of measurements allow quantification of drag as a function of both angle of attack and spanwise location. A summary of test cases can be found in Table 1

\section{Data Processing}

The following section outlines the data analysis process, including equations used to post-process the balance and the wake rake data, the wind tunnel corrections for three-dimensional effects and post-processing parameters for the PIV system. 


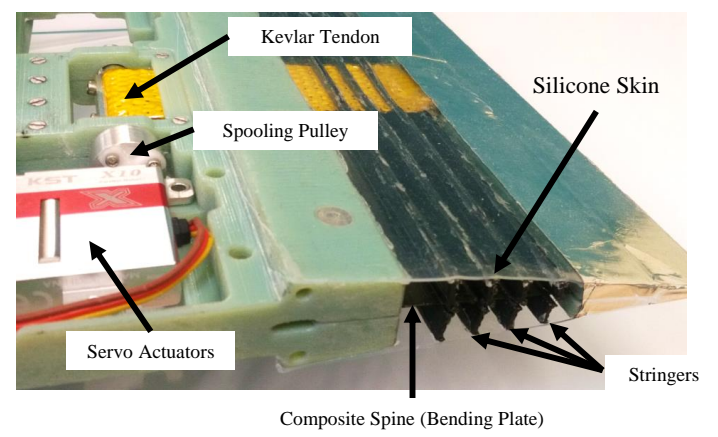

Fig. 4 FishBAC structure and actuation mechanism

Table 1 Wind tunnel test configurations and test cases

\begin{tabular}{cccc}
\hline Configuration & Actuation Input Angle & PIV & Videogauge \\
\hline Baseline & N/A & No & No \\
Flap & $\delta=\left[-20^{\circ}:+10^{\circ}:+30^{\circ}\right]$ & Yes & No \\
FishBAC & $\delta=\left[+0^{\circ}:+10^{\circ}:+40^{\circ}\right]\left(\delta=-10^{\circ}\right.$ PIV only $)$ & Yes & Yes \\
\hline
\end{tabular}

\section{A. Force Balance Data}

Aerodynamic forces and moments were measured by the two force balances, individually, and then combined to calculate the total resultant forces and moments. Each balance measures in its own respective coordinate frame. Since the bottom balance rotates with the turntable while the top balance is fixed, the forces measured by the bottom balance need to be converted to the global coordinate frame. Hence, the total lift force is calculated by

$$
L=F_{y_{1}} \cos \left(\alpha_{u}\right)-F_{x_{1}} \cos \left(\alpha_{u}\right)-F_{y_{2}} \quad \text { and } \quad D=F_{x_{1}} \cos \left(\alpha_{u}\right)+F_{y_{1}} \cos \left(\alpha_{u}\right)+F_{x_{2}}
$$

where $F_{x_{1}}$ and $F_{y_{1}}$ correspond to the bottom balance, $F_{x_{2}}$ and $F_{y_{2}}$ correspond to the top balance and $\alpha_{u}$ is the rotation angle of the turntable corresponding to the angle of attack before wind tunnel correction is applied (as presented in Section V.C. . Furthermore, zero wind speed tare measurements were recorded before and after each angle of attack sweep. These were later subtracted from the force balance data set to account for any offsets or time drift in the measured values.

Obtaining accurate two-dimensional drag measurements from balance setups such as the one used can be difficult, due in part to the large differences between lift and drag forces, the range of the load cells used, and the presence of end gaps and wall effect. Therefore, wake survey measurements were used to give more accurate two-dimensional measurements of drag using wake momentum deficit [28].

\section{B. Wake Rake Data}

Drag can be measured by comparing the momentum of the air in the freestream against that measured in the flow behind the wing model. This method assumes that the wind tunnel walls are parallel and with negligible shear stresses. 
This theory is based on the assumption that, as the flow passes over a wind tunnel model, it suffers a loss of momentum that is equal to the profile drag of the body [28]. Profile drag coefficient can then be estimated using the expression,

$$
C_{d_{0}}=2 \int\left(\sqrt{\frac{H-p}{H_{0}-p_{0}}}-\frac{H-p}{H_{0}-p_{0}}\right) \frac{d y}{c}=2 \int\left(\sqrt{\frac{q}{q_{0}}}-\frac{q}{q_{0}}\right) \frac{d y}{c}
$$

where $H, p$ and $q$ are the total, static and dynamic pressures at the wake, respectively, and $H_{0}, p_{0}$ and $q_{0}$ are the same pressure quantities in the freestream. Additional information regarding these wake rake survey measurements can be found in Rivero et al. (2020) [29].

\section{Wind Tunnel Corrections}

To correct for three-dimensional effects, wind tunnel corrections are applied to account for solid and wake blockage and streamline curvature. The correction factors implemented in this study are the standard ones given by Barlow et al. [28]. These factors are then used to correct the lift and drag coefficients, as well as the angle of attack and Reynolds number. A detailed derivation of these correction factors can be found in Rivero et al. (2020) [29].

\section{Particle Image Velocimetry}

Two-dimensional two component PIV measurements were performed to measure the flow velocity in a portion of the near field wake of both FishBAC and flap configurations. A $200 \mathrm{~mm} \times 200 \mathrm{~mm}$ calibration plate was used to define the measuring area, which was placed at a spanwise location of $0.467 b$ (i.e. just below the midspan). This location is well outside the wind tunnel wall-effect regions, and is very near the plane of symmetry of the wing, and so the measurements are as two-dimensional as possible (considering that the flap's control horns introduce three-dimensional flow properties at and around their location). All PIV measurements were performed at a fixed angle of attack of $\alpha=5^{\circ}$ to ensure attached flow. To compare the impact of camber deflection on wake size and velocity for both the morphing and hinged trailing edge devices, PIV measurements were taken for a total of four FishBAC and flap deflections.

For each configuration, a total of 1000 images were taken at a frequency of $10 \mathrm{~Hz}$, with a differential time of $d t=13.5 \mu$ s between the two laser pulses. To reduce noise, a minimum image intensity was calculated for each data set, and then subtracted from all images in that set. Post-processing of images was performed using LaVision® DaVis 10 software. A seeding particle size of $1 \mu \mathrm{m}$ was used throughout the experiment. An interrogation area of 48 pixels was chosen (equivalent to $3.6 \mathrm{~mm}$ in both directions), as suggested by DaVis 10 for a flow velocity of $30 \mathrm{~m} / \mathrm{s}$. With a seeding particle size of $1 \mu \mathrm{m}$, the authors aimed to achieve a seeding density of 16-20 particles per interrogation area. Lastly, a Tamron 70-200 mm F/2.8 DI VC USD G2 lens with a standard Nikon mount was used. The focal length was fixed at $150 \mathrm{~mm}$ for all measurements, and a maximum aperture was set to maximize the amount of light to reach the camera sensor. 


\section{E. Videogauge Point Tracking System}

To study the FishBAC's deformation under aerodynamic loads, displacements were measured at a number of points along the FishBAC's chord and span. As mentioned in Section III.A.2. $5 \mathrm{~mm}$ bulls-eye stickers were used as tracking points. These tracking points were placed every $50 \mathrm{~mm}$ along the span at the trailing edge, as well as every $10 \mathrm{~mm}$ along the chord at the following locations: mid-span, three-quarter-span, chordwise free edge and at the center of the tendon. Three-dimensional position and displacements of each point were directly obtained from the point tracking software, and time averages are calculated at each point. The presence of outliers was determined based on shape continuity, and were later removed from each data set.

Additionally, these displacement measurements were complemented with actuation torque input estimates. Torque can be calculated by first measuring the current draw of each actuator, and then assuming a linear relationship between the two [30], such that

$$
T=\epsilon k_{t} I
$$

where $\epsilon$ is the mechanical efficiency factor of the actuation mechanism and $k_{t}$ is the torque constant-which defines the linear relationship between mechanical torque and current. The torque constant of the KST X10 servo actuators was obtained in a previous experiment by Rivero et al. (2018) [31], and it has an estimated value of $k_{t}=0.82 \mathrm{~N} \mathrm{~A}^{-1}$ - for a driving voltage of $6 \mathrm{~V}$, which was used throughout the wind tunnel test. Four (one per actuator) LEM ${ }^{\circledR} 6$ A CASR 6-NP Hall Effect current sensors are used. These sensors measure the strength of the magnetic field induced by the current flow through the the actuator leads and generate an output voltage that is directly proportional to the magnitude of current—at a rate of $312.6 \mathrm{~mA} \mathrm{~V}^{-1}$. Finally, voltage and current measurements were recorded using a National Instruments ${ }^{\circledR}$ USB-6211 data acquisition card. Lastly, the mechanical actuation system efficiency (including tendons) was obtained experimentally by comparing analytical predictions [32] with experimental displacements in absence of aerodynamic loads, and its estimated value is $\epsilon=0.503$.

\section{Results}

The following section presents the results of this wind tunnel test campaign. These include a comparison between the aerodynamic behavior of the FishBAC and the flap using both balance data and pressure-based wake survey measurements. Finally, PIV and VG results are also shown.

\section{A. Aerodynamic Forces}

This subsection directly compares the NACA 23012 rigid airfoil configuration described in Section III.B with previous experimental data from the literature and 2D XFOIL predictions. Fig. 55shows both experimental and predicted 
lift and drag curves. The experimental data was obtained from Ashenden et al. [33] and Pouryoussefi et al. [34], which both tested at similar Reynolds numbers ( $R e=550,000$ and $R e=600,000$, respectively). However, it is important to note that these two experiments used pressure taps on the surface to obtain both lift and drag. Hence, some discrepancies are expected due to differences in measuring techniques.

Fig. 5]shows that the lift curve measured in this work is similar to Pouryoussefi et al.'s results [34], whereas Ashenden et al. [33] has a more similar behavior to the XFOIL predictions. The reduction in measured lift performance could be due to the different measuring techniques: Ashenden et al. measured local section lift coefficient using pressure taps, whereas the present results correspond to the average total lift as measured by the force balances. Although 3D effects exist due to the presence of wall gaps of around $2 \mathrm{~mm}$ (i.e. $0.75 \%$ chord), these will not compromise the conclusions of this experiment as the same wing setup was used to test all three configurations (baseline, flap and FishBAC).

Moreover, Leishman [35] and Jacobs and Sherman [36] show NACA 23012 experimental maximum lift coefficients for similar Reynolds numbers. Both results show a maximum lift coefficient estimates of $C_{L_{\max }} \approx 1.25$, which is closer to the $C_{L_{\max }} \approx 1.14$ obtained in this experiment and suggests that XFOIL may over-predict the maximum lift coefficient. Lastly, it is important to point out that the presented results suggest the possibility of a slight angle of attack offset in the current wing model setup, as the lift coefficient at $\alpha=0^{\circ}$ is perhaps closer to zero than expected for this cambered airfoil (Fig. 5).

When analyzing the drag coefficient results in Fig. 5. it is observed that the obtained experimental results (wake rake) are similar to those obtained by Ashenden et al. [33]. Unlike lift coefficient, drag coefficient was calculated using local section wake rake data instead of average forces (force balance). This difference in measuring technique is a likely explanation of the better agreement between the currently measured drag results with Ashenden et al.'s results. It is important to point out that due to the difference in magnitude between lift and drag forces (i.e. lift is two orders of magnitude greater than drag) and the force balances being calibrated to measure forces up to $4500 \mathrm{~N}$, a wake rake is
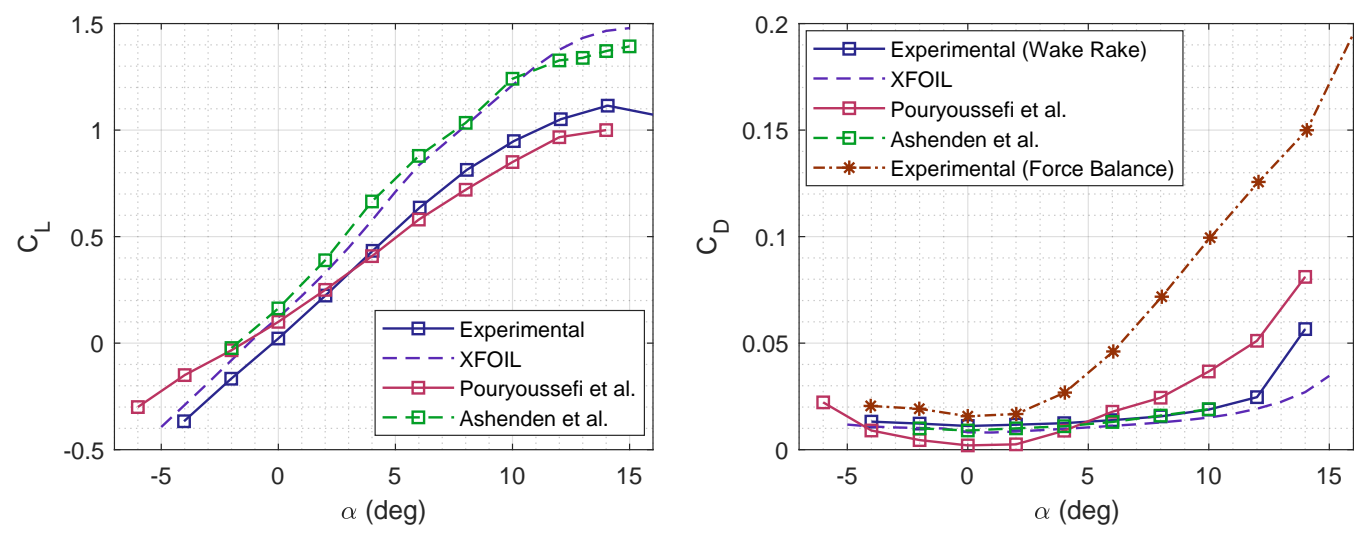

Fig. 5 NACA 23012 rigid configuration experimental lift and drag curves vs 2D panel method results (XFOIL). 
more suitable to measure drag. Consequently, lift and drag measurements present different experimental uncertainties, which has been considered in the data analysis.

In order to assess repeatability and estimate the uncertainty in the obtained lift coefficients, four different angle of attack sweeps were performed using the baseline configuration (Fig. 6). An maximum relative standard deviation of $2.92 \%$ was calculated for these lift coefficient estimates. Furthermore, a maximum standard deviation of $0.3 \%$ was calculated across all pressure measurements performed using the wake rake. These low levels of deviation indicate that the lift and drag measurements are highly repeatable. Furthermore, if these two relative standard deviations are combined (by addition), it can be stated that the lift-to-drag ratios have an uncertainty of $3.22 \%$.

In summary, the NACA 23012 baseline results show similar trends to experimental and XFOIL data, especially given the variation seen between different sets of results in the literature. However, it is observed that the obtained results have a lower maximum lift coefficient than some of the previous results and those from XFOIL. One potential reason for this is the presence of aluminum tape at the various connection points between subsections of the model, which could potentially affect the boundary layer. However, it is very likely that the main cause of this reduction in maximum lift coefficient is the existence of $3 \mathrm{D}$ effects in this wind tunnel setup. It is worth noting that the primary aim of this study is to compare the FishBAC to the flap, and so the relative (as opposed to absolute) aerodynamic performance is of key importance, and any performance impacts from the construction of the model are present in both.

\section{FishBAC vs. Flap}

The measured lift and drag coefficients for the FishBAC and flap are shown in Figs. 7] and 8, respectively. It is observed in these figures that deflecting both the FishBAC and flap has a similar impact on the lift curves. As expected, increasing camber shifts the lift curve up and to the left, increasing lift at a given angle of attack, but also lowering the angle at which stall occurs. In terms of lift control authority, the FishBAC and flap show an overall $\Delta C_{L} \approx 0.55$
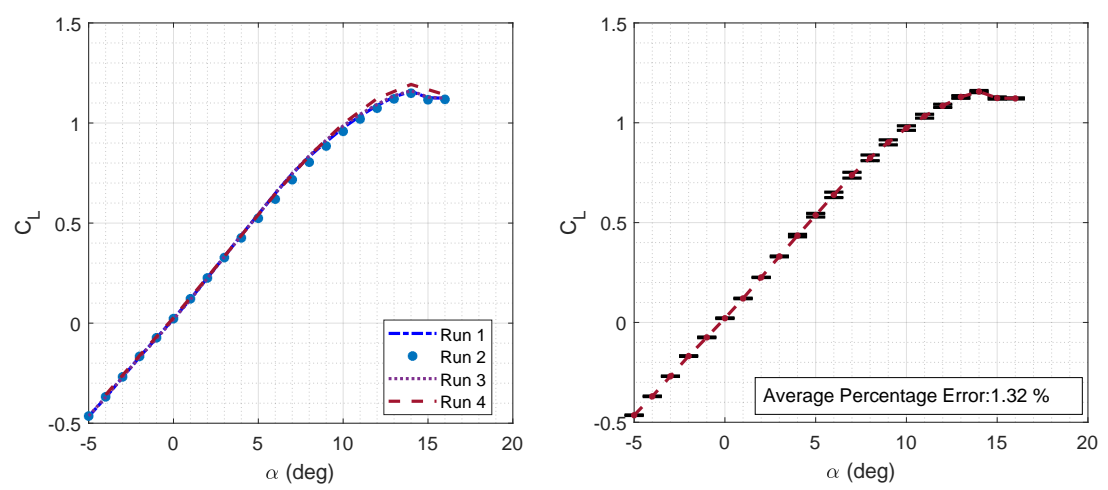

Fig. 6 NACA 23012 lift curve measured at four different runs (left) and resulting averaged data and error bars (right) — where error bars correspond to the standard deviation at each angle of attack. 
and $\Delta C_{L} \approx 0.57$, respectively — considering trailing edge down deflections only. Note that, although the FishBAC can deflect upwards, these downward deflections are not presented as these measurements presented a high levels of experimental uncertainty. It is also noticed that for both devices the amount of additional lift $\left(\Delta C_{L}\right)$ generated for each deflection increment diminishes with increasing deflections, as observed in previous studies [37].

While the FishBAC and flap both have a very large lift control authority, comparison of the associated drag coefficients in Figs. 7 8 shows that the flap configuration incurs a much higher drag penalty. This drag increase over the baseline airfoil ranges from $74 \%$ to $80 \%$ for the $\delta=+10$ and $\delta=+30$ configurations, respectively (Fig. 8). To directly compare aerodynamic efficiency, lift-to-drag ratios as a function of both angle of attack and lift coefficient are presented in Figs. 9 and 10 for FishBAC and flap, respectively. It is observed that, for a given deflection, the FishBAC achieves starkly higher lift-to-drag ratios across the operating envelope.
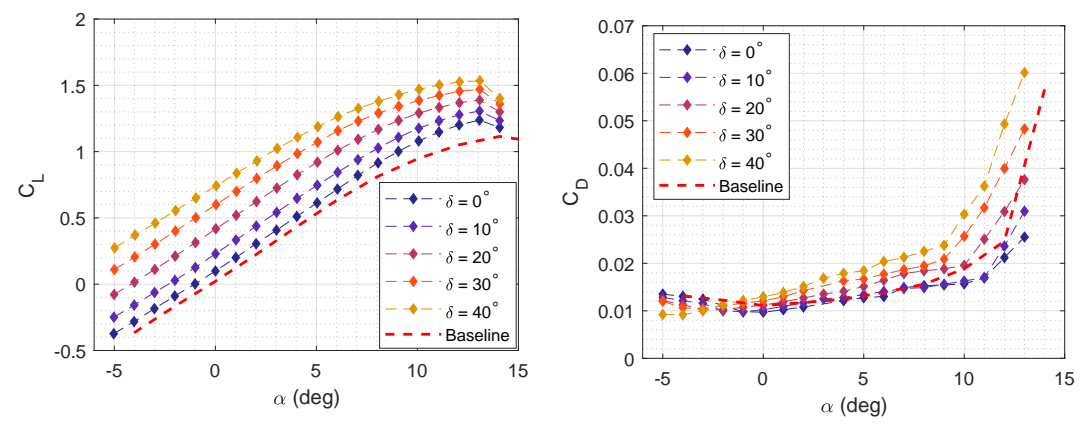

Fig. 7 FishBAC lift and drag coefficients as a function of angle of attack at various actuation input angles.
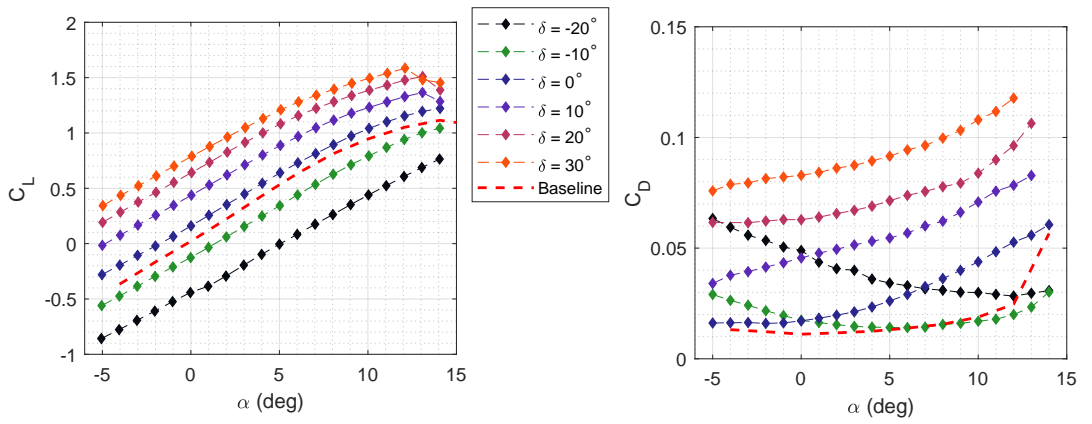

Fig. 8 Flap lift and drag coefficients as a function of angle of attack at various actuation input angles. 

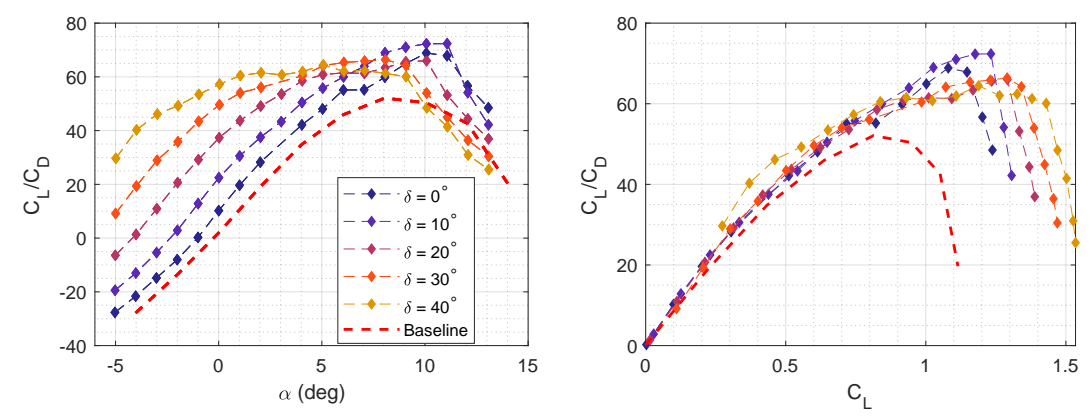

Fig. 9 FishBAC aerodynamic efficiency as a function of both angle of attack and lift coefficient.
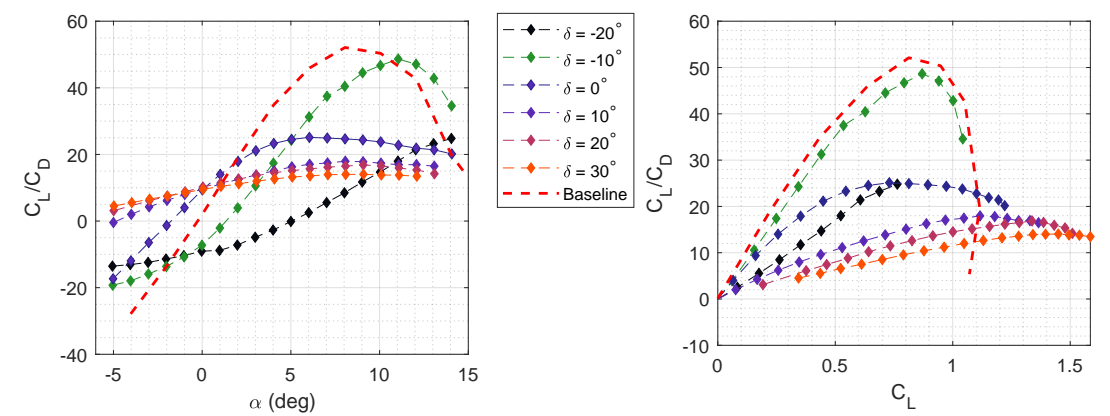

Fig. 10 Flap aerodynamic efficiency as a function of both angle of attack and lift coefficient.

To further visualize these efficiency improvements and to compare the performance of the three tested configurations, an 'efficiency envelope' that displays each configuration's best obtainable lift-to-drag ratio as a function of lift coefficient, is introduced. By doing so, the two parameters that can vary lift coefficient—angle of attack and actuation input—are condensed into a single curve that describes the best obtainable performance for each configuration (Fig. [11] [38]. This condensed metric is particularly useful when comparing the aerodynamic performance of different trailing edge devices (e.g. FishBAC vs flap), as it can establish a direct comparison between different configurations that is independent of parameters that may vary with each specific device—e.g. actuation inputs, camber deflections, angles of attack and flap angles. The key factor is that each device is allowed to perform to the best of its abilities.

These efficiency envelopes show that the FishBAC achieves significantly higher lift-to-drag ratios than the flap configuration over the full range of angles of attack tested. This improved efficiency increase ranges from 160\% to $27 \%$, for low $\left(0^{\circ}<\alpha<5^{\circ}\right)$ and high $\left(\alpha>10^{\circ}\right)$ angles of attack, respectively (Fig. 12). Furthermore, when shown in terms of lift coefficient - the control of which is the goal of camber change-it can be seen that the FishBAC performs better over the full range of lift coefficients achieved, and significantly better at moderate to high lift coefficients (i.e. $C_{L}>0.8$ ). These efficiency improvement is $200 \%$ or greater for $C_{L}=1.1-1.25$. Even in the case of lower lift coefficients, where the most efficient deformations of the active camber devices are effectively zero, the FishBAC has lift-to-drag ratios that are at least $16 \%$ higher than the flap's. Which is to say that even when the device is not being used, the FishBAC is still 
significantly more efficient (Fig. 13.

In summary, the FishBAC is more aerodynamically efficient than the flap at all angles of attack and lift coefficients. However, the benefit of camber morphing is particularly remarkable at higher lift coefficients. The minimum efficiency improvement is of $16 \%$ at $C_{L} \approx 0.5$, whereas improvements above $200 \%$ are observed at higher lift coefficients. It is important to note that the FishBAC's drag measurements were performed at a 'high drag' region-i.e. near the actuation tendon, where the largest camber deflections occur and tunnel wall-model interactions are more likely—whereas the flap's drag measurements were performed at midspan, far away from the external control horns required to drive the flap and any wall effects. Lastly, it is important to note that differences between undeflected FishBAC and flap and baseline results exist. In the FishBAC's case, the $\delta=0^{\circ}$ shows higher lift than baseline NACA 23012. This is most likely due to the FishBAC having a small downward deflection, induced by either a small positive offset on the actuation input or an uneven skin tension between the top and bottom surfaces. Moreover, in the flap's case, the increased lift is potentially due to a small positive deflection angle due to an input offset. This offset is likely due to a mismatch between the actuation angle input and the flap angle. This is consistent with the higher drag results for the undeflected configuration (Fig. 7). The impact of these small offsets on the overall results is minimal though, as sweeps for both devices are presented and the efficiency envelopes, in particular, help mitigate the impact of camber offsets on the comparison.
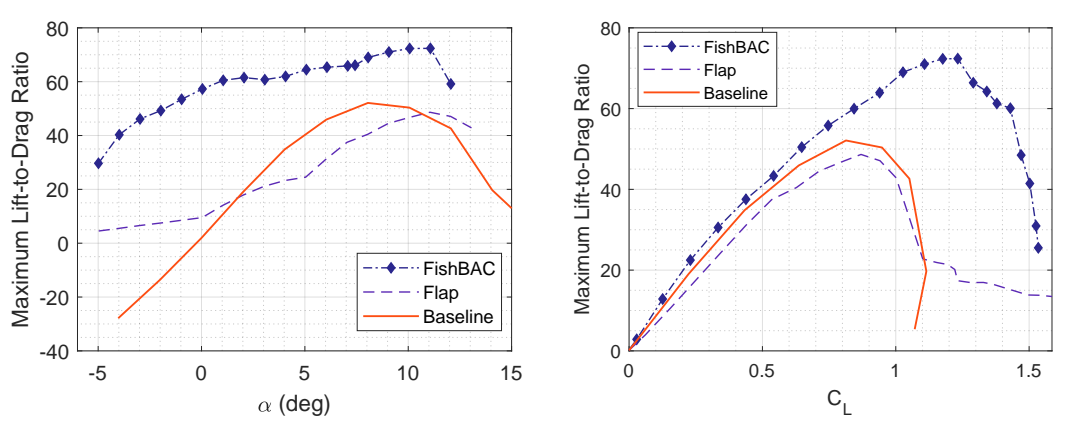

Fig. 11 Efficiency envelope, where the best lift-to-drag ratios that both FishBAC and Flap can achieved, are displayed.

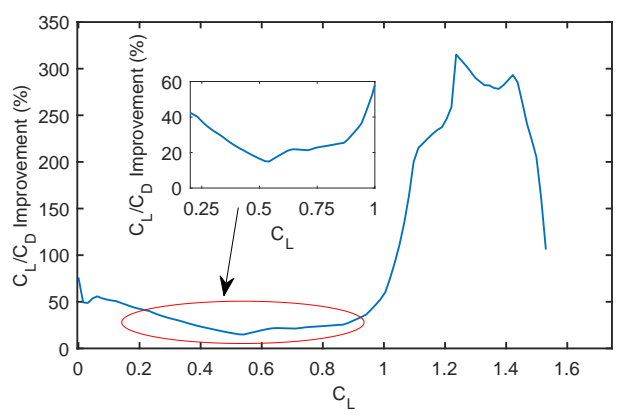

Fig. 12 Percentage improvements in FishBAC aerodynamic efficiency-compared to flap. 


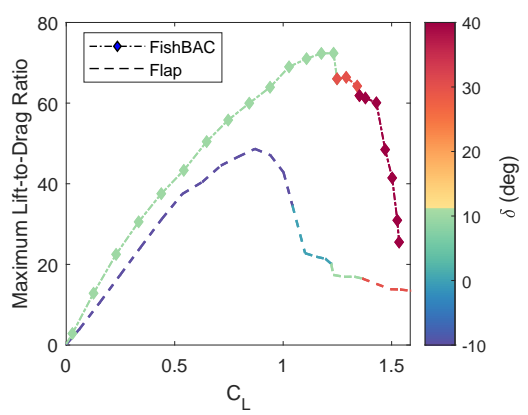

Fig. 13 Efficiency envelope shown in Fig. 11 as a function of actuation input angle of both FishBAC and flap.

\section{B. Spanwise Wake Rake Drag Measurements}

Wake rake survey measurements were performed at different spanwise locations to further investigate the variation in drag along the span. For these measurements, both angle of attack and actuation input angle remained constant. Fig. 14 presents FishBAC wake rake drag measurements at a fixed angle of attack $\left(\alpha=5^{\circ}\right)$ and maximum actuation input $\left(\delta=+40^{\circ}\right)$. The pressure ratio distributions on the top half (i.e the portion of the wing adjacent to the top force balance as seen in Fig. 22 of the wing span are only shown since the testing and actuation configuration is symmetrical about the midspan of the wing. Results show a drag coefficient variation of $22 \%$ between the lowest and highest values-at midspan and at quarter-span, respectively. The wake distribution data also shows that the wake shifts down in the thicknesswise direction as the rake scans along the span, having a maximum displacement of $40 \mathrm{~mm}$ moving from about the midspan close to the tendon. This is likely due to variation in camber along the span due to elastic washout, as mentioned previously. Additionally, the pressure ratio peak values and distribution are fairly uniform, with a maximum variation of less than $2.5 \%$ between the lowest and highest value. These observed differences in dynamic pressure ratio explain the relatively low variation in drag coefficients.

Similarly, Fig. 15 shows wake rake drag measurements for the flap at several spanwise locations. Once again, the angle of attack was fixed at $\alpha=5^{\circ}$, but the actuation deflection input was fixed at $\delta=+20^{\circ}$. The higher steadiness of the pressure data makes the $\delta=+20^{\circ}$ case more suitable to be displayed than the $\delta=+30^{\circ}$ case, although the lift coefficient in this case is slightly lower that the FishBAC configuration $\left(\delta=+40^{\circ}\right)$ presented in Fig. 14. In order to quantify the drag increase due to the presence of external actuator control horns, extra measurements were performed around their location. If the very high drag region near the control horns is excluded, the flap shows a higher variation in drag coefficient of around 55\% between the lowest (at midspan) and highest (at quarter-chord) values. Additionally, a $466 \%$ increase in drag coefficient is observed at the control horn. This increase shows that the control horn significantly disrupts the flow and, therefore, justifies the decision to perform all flap's drag measurements presented in Section VI.A.1 at midspan (to avoid over-penalizing the flap). Moreover, it is observed that near the control horn there are two separate but overlapping wake regions, perhaps due to the control horn shedding its own wake. 


\section{Particle Image Velocimetry}

PIV measurements were performed to visualize the differences in the wakes created by the FishBAC and the flap. These results are useful to further establish the reasons for the significant improvement in performance seen with the FishBAC. These measurements were performed at actuation input angles between $\delta=-10^{\circ}$ and $+20^{\circ}$, in increments of $\delta=10^{\circ}$. To further understand the wake behavior, the results are analyzed using four different metrics: time-varying and average velocity fields for measuring wake thickness, and Reynolds stresses and turbulence kinetic energy for measuring turbulence levels. It is worth mentioning that, even though the flap's and FishBAC's PIV measurements were not performed at the same lift coefficient, Figs.7 7 s show that both devices have very similar lift coefficients at $\alpha=5^{\circ}$. Therefore, a fair comparison between the two devices can be established.

\section{Velocity Fields}

Fig. 16 shows FishBAC vs. flap time-varying velocity fields ( $0.1 \mathrm{~s}$ intervals) when actuation input is set to $\delta=+20^{\circ}$. These results show the unsteady nature of the flap case, where a bluff body like vortex sheet seems to have developed. On the contrary, the wake in the FishBAC case is significantly narrower and more stable. To assess how wake thickness varies with increasing camber deflection, time-averaged velocity fields across a $100 \mathrm{~s}$ time interval $(10 \mathrm{~Hz}$ sampling frequency) are calculated at different actuation input angles.

Fig. 17 shows these time-averaged velocity fields for both the FishBAC and flap. Unlike the FishBAC, the wake thickness of the flap increases significantly with deflection. This wake thickness was calculated by measuring the distance, across the wake, at a location of $0.1 c$ aft of the trailing edge (Table 2). The wake limits were assumed to be the points when the flow speed is equal to at least $99 \%$ of the freestream velocity. Results show that the wake thickness of the FishBAC does not significantly grow with increasing deflection (over the range of $\delta$ shown here), achieving a stable value of approximately $16 \mathrm{~mm}$ (i.e. $6 \%$ of chord length). These results are consistent with the marginal drag increases with increasing deflection that are observed in Fig. 7 and suggest that the flow remains attached over the FishBAC surface. Conversely, it is observed that the the flap's wake thickness ranges from $28.59 \mathrm{~mm}$ to $47.02 \mathrm{~mm}$ (i.e. $10.5 \%$
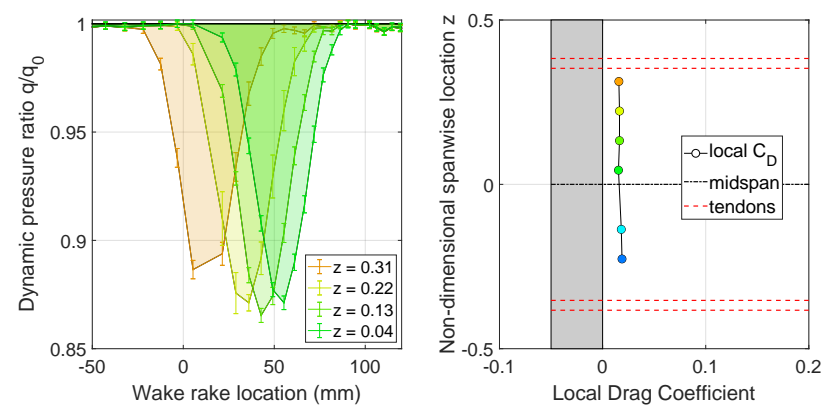

Fig. 14 FishBAC wake distribution along the span (left) and drag coefficient vs spanwise location (right) $\left[\alpha=5^{\circ}\right.$, $\left.\delta=+40^{\circ}\right]$. 

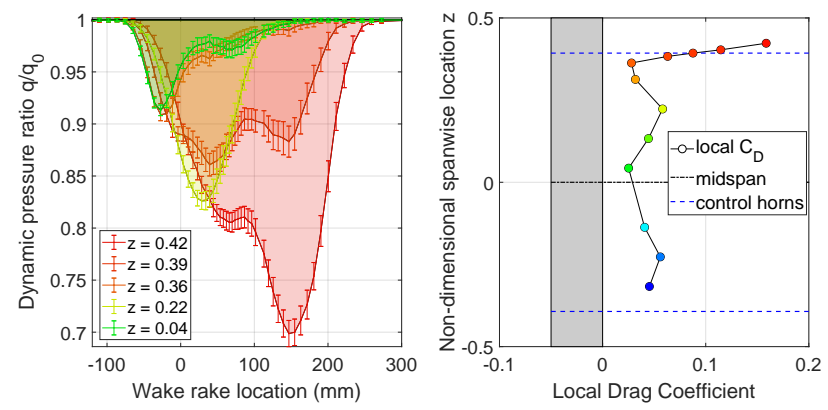

Fig. 15 Flap wake distribution along the span (left) and drag coefficient vs spanwise location (right) $\left[\alpha=5^{\circ}\right.$, $\left.\delta=+20^{\circ}\right]$.

and $17.5 \%$ of chord length), for inputs of $\delta=0^{\circ}$ and $\delta=+20^{\circ}$, respectively. When compared to the FishBAC, these flap results represent an increase of between two to three times in wake thickness, which correlates to the significant higher drag shown in Section VI.A.1. Also, it is conceivable that the flap induces earlier flow separation due to the sharp change in camber shape, whereas the FishBAC deflects in a smooth and continuous way and with no structural gaps, thus keeping the flow attached to its surface.

Table 2 FishBAC's and Flap's wake thickness for different actuation inputs. Results correspond to a fixed angle of attack of $\alpha=5^{\circ}$ and freestream velocity of $V=30 \mathrm{~m} / \mathrm{s}$.

\begin{tabular}{cccc}
\hline Configuration & Input Angle $(\mathrm{deg})$ & Wake Thickness $(\mathrm{mm})$ & Normalized Wake Thickness $(t / c)$ \\
\hline \multirow{3}{*}{ FishBAC } & -10 & 16.1 & 0.060 \\
& 0 & 14.6 & 0.054 \\
& +10 & 16.2 & 0.060 \\
& +20 & 16.3 & 0.060 \\
\hline \multirow{3}{*}{ Flap } & -10 & 29.9 & 0.11 \\
& 0 & 28.6 & 0.11 \\
& +10 & 31.9 & 0.12 \\
\hline
\end{tabular}

\section{Turbulence}

Turbulence is assessed by two different criteria: Reynolds stresses and turbulence kinetic energy. Reynolds stresses are a way to quantify velocity fluctuations due to turbulence by measuring the additional momentum fluxes due to unsteady turbulence motion [39]. Fig. 18 shows the normalized Reynolds stress components $\overline{u^{\prime} u^{\prime}}$ and $\overline{v^{\prime} v^{\prime}}$. Note that both quantities have been normalized by density and freestream velocity squared (i.e. $\rho_{\infty} V_{\infty}^{2}$ ). A large value of $\overline{u^{\prime} u^{\prime}}$ indicates the presence of strong turbulent shear layers downstream, whereas large values of $\overline{v^{\prime} v^{\prime}}$ shows regions where vortices are propagating in the streamwise direction [40]. Results show that the flap's Reynolds stresses $\overline{u^{\prime} u^{\prime}}$ and $\overline{v^{\prime} v^{\prime}}$ are at least one order of magnitude higher than in the FishBAC. In fact, the turbulence structure in the wake of the flap 
is similar to that of a blunt trailing edge airfoil (see Manolesos and Voutsinas (2016) for example [40]). This is in agreement with the snapshots shown in Fig. 16. It is conceivable that the vortices are shed in an alternating manner from the flap sharp trailing edge (lower vortex) and from the hinge (top vortex). Also, it is observed in the FishBAC's results that there are two regions where $\overline{u^{\prime} u^{\prime}}$ is non-zero, which define the limits of the airfoil wake.

Lastly, to measure the turbulence intensity, the turbulence kinetic energy (TKE) in both FishBAC and flap cases is calculated. TKE is defined as one-half of the sum of the squares of the velocity fluctuations [41], such that

$$
\mathrm{TKE}=\frac{1}{2}\left({\overline{u^{\prime}}}^{2}+{\overline{v^{\prime}}}^{2}\right)
$$

Fig. 19 shows the turbulence kinetic energy of both FishBAC and flap when actuation input is equal to $\delta=0^{\circ}$ and $\delta=+20^{\circ}$, respectively. It is observed that, when deflected, the flap's turbulence kinetic energy is approximately one order of magnitude higher than the FishBAC's, which shows the significantly higher turbulence intensities associated with flap deflections. It can also be seen that there is much less turbulence for the FishBAC than the flap even in the case of no deflection, which corroborates the conclusions made above with regards to the improvements in lift to drag ratio.
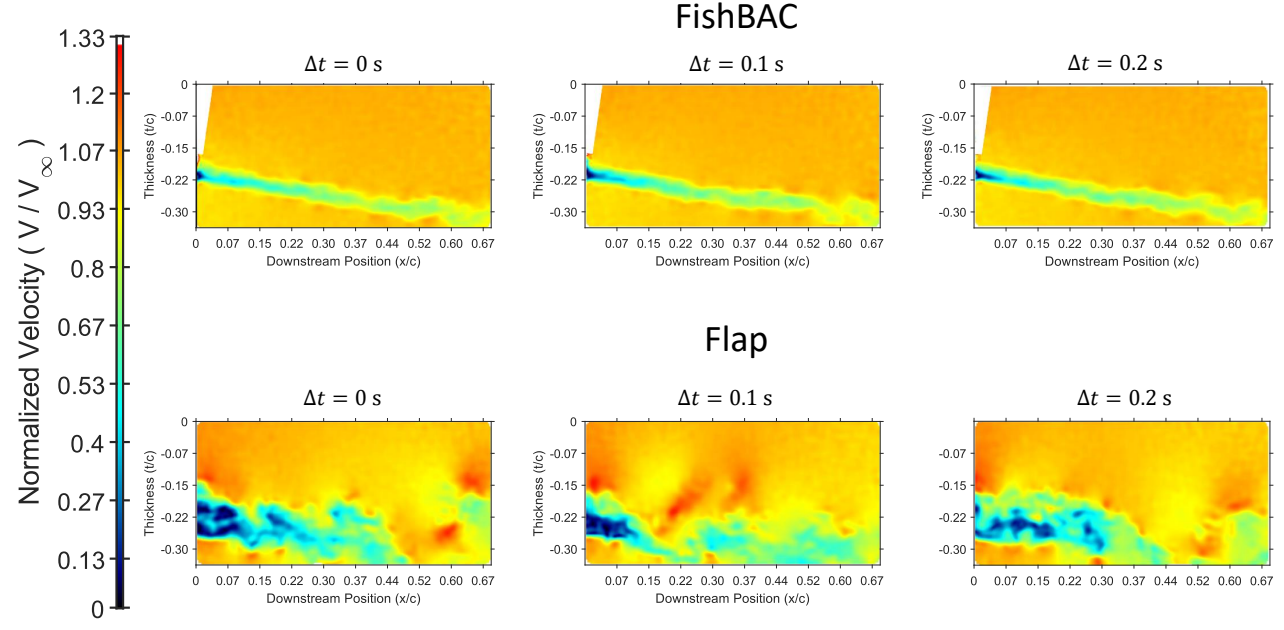

Fig. 16 FishBAC (top) and Flap (bottom) instantaneous velocity fields under uniform actuation (symmetric actuation inputs about the midspan). The freestream velocity and angle of attack for all these images are $V=$ $30 \mathrm{~m} / \mathrm{s}$ and $\alpha=5^{\circ}$, respectively. 

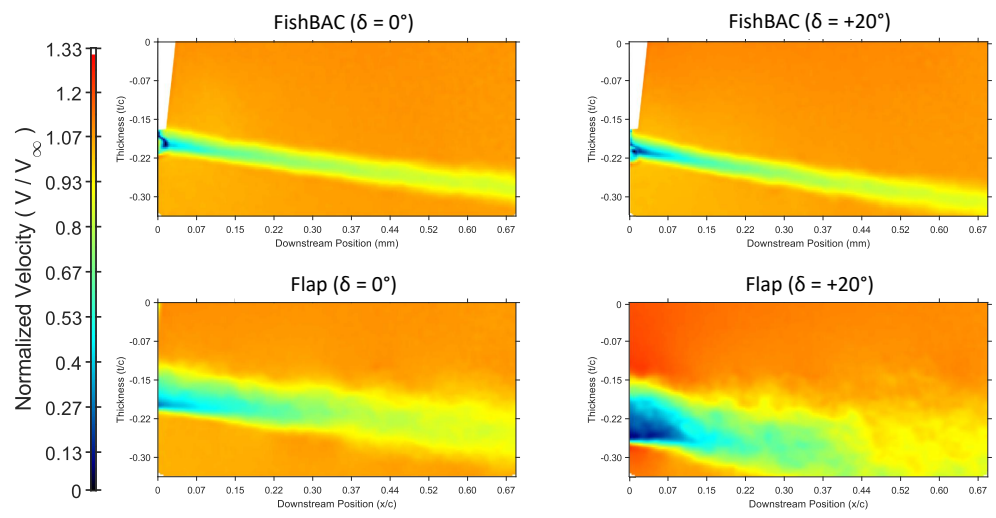

Fig. 17 FishBAC (top) and Flap (bottom) time-averaged velocity fields under uniform actuation (symmetric actuation inputs about the midspan). The freestream velocity and angle of attack for all these images are $V=$ $30 \mathrm{~m} / \mathrm{s}$ and $\alpha=5^{\circ}$, respectively.
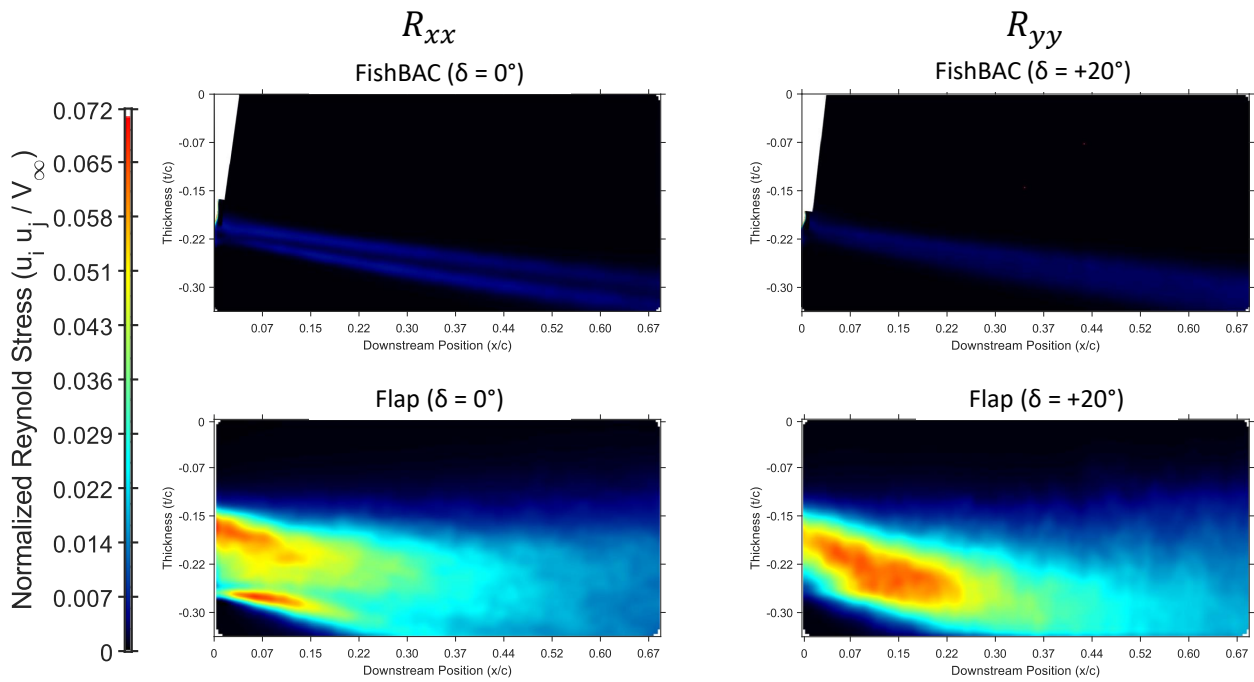

Fig. 18 FishBAC (top) and Flap (bottom) Reynolds stresses at an actuation input angle of $\delta=+20^{\circ}$ (symmetric actuation inputs about midspan). The images on the left correspond to $\overline{u^{\prime} u^{\prime}}\left(R_{x x}\right)$, whereas the images on the right correspond to $\overline{v^{\prime} v^{\prime}}\left(R_{y y}\right)$. The freestream velocity and angle of attack for all these images are $V=30 \mathrm{~m} / \mathrm{s}$ and $\alpha=5^{\circ}$, respectively. 

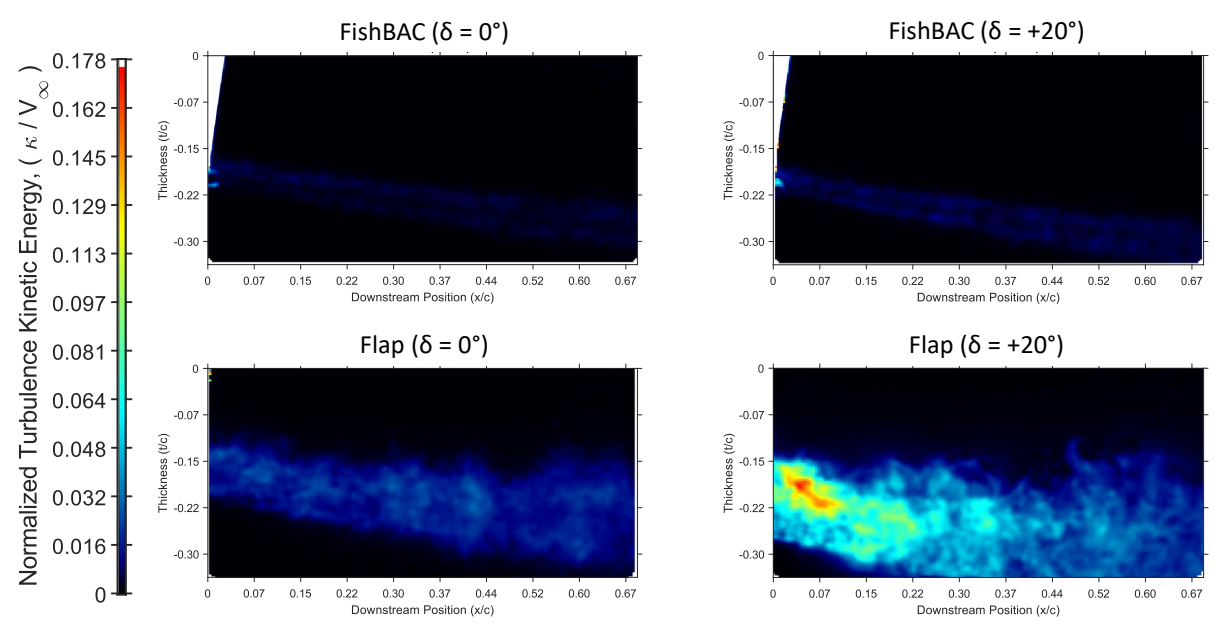

Fig. 19 FishBAC (top) and Flap (bottom) turbulence kinetic energy (TKE). Images on the left correspond to an actuation input angle of $\delta=0^{\circ}$, whereas images on the right correspond to $\delta=+20^{\circ}$ (symmetric actuation inputs about midspan). The freestream velocity and angle of attack for all these images are $V=30 \mathrm{~m} / \mathrm{s}$ and $\alpha=5^{\circ}$, respectively.

\section{Displacements: Point Tracking System}

Following on from the PIV measurements, three-dimensional displacement fields of the morphed FishBAC under aerodynamic loads were measured using a point tracking stereo videogauge system. These measurements were performed at two angles of attack—at $\alpha=0^{\circ}$ and $\alpha=5^{\circ}$-and at a freestream velocity of $V=30 \mathrm{~m} \mathrm{~s}^{-1}$. Note that, for all these configurations, the chordwise displacements were measured at the center tendon and at the three-quarter span, whereas the spanwise displacements were measured along the trailing edge. Fig. 20 shows the FishBAC displacement with varying actuation input at $\alpha=5^{\circ}$, along the chordwise and spanwise directions, respectively. Table 4 shows a summary of maximum transverse displacements at three different locations—-midspan, three-quarter-chord and tendon—for each test configuration. Lastly, Table 3 shows the actuation torque estimates for each given flow condition and actuation input, which were calculated using Eq. 33. The average uncertainty in this measurements was estimated to be $48.5 \mu \mathrm{m}$.

As expected, it is observed in Table 4 that aerodynamic loads reduce the FishBAC's maximum displacements (at tendon) by between $30 \%$ and $40 \%$ for the $\alpha=0^{\circ}$ case, and by between $42 \%$ and $60 \%$ for the $\alpha=5^{\circ}$ case. This is consistent with the fact that aerodynamic pressure increases actuation requirements, and increasing angle of attack increases aerodynamic loads. Additionally, results show that the highest actuation loads are applied at the $V=30 \mathrm{~m} \mathrm{~s}^{-1}$, $\alpha=0^{\circ}$ case, followed by the zero freestream and the $V=30 \mathrm{~m} \mathrm{~s}^{-1}, \alpha=5^{\circ}$ cases. Lastly, to compare the actuation energy requirements of both FishBAC and flap, the total power draw by the entire actuation mechanism was measured. Table 5 shows the average power draw as a function of actuation input angle. Results show that, while the power draw for both wings is quite low in real terms $(\approx 20 \mathrm{~W}$ max $)$, the FishBAC does require significantly more power than the 
flap (on average $4 x$ the power draw) to achieve the desired changes in camber. These results are consistent with the fact that camber morphing devices have both the elastic stiffness and aerodynamic loads resisting the change in shape, whereas the flap only has the aerodynamic loads and a small hinge friction resisting the motion. Results shown in Table 5 are then plotted in Fig. 21, where it is observed that the FishBAC power draw increases significantly with increasing actuation input. Therefore, there are not only diminishing returns in terms of change in lift coefficient between each actuation input step, but also in the amount of energy that it is required for each deflection increment. This, combined with the results in Fig. 11, implies that the best achievable camber morphing performance, when considered from a system level perspective, will likely use low to moderate deflections for all but the largest of desired lift coefficients.
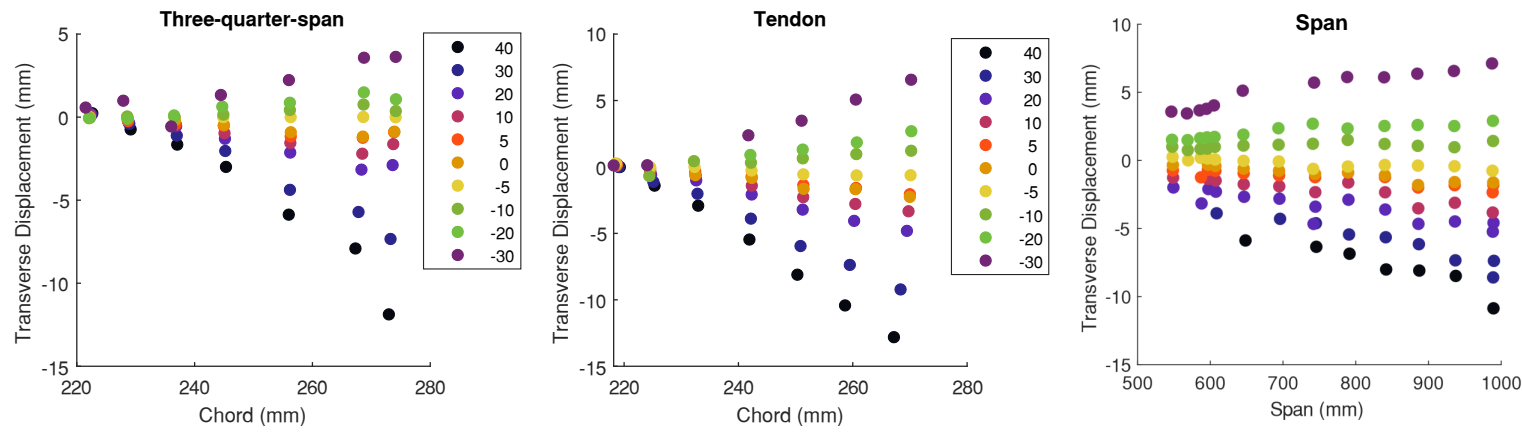

Fig. 20 FishBAC's chordwise deflection about the three-quarter-span (left) and tendon (right) locations. Both freestream velocity and angle of attack were fixed at $V=30 \mathrm{~m} \mathrm{~s}^{-1}$ and $\alpha=0^{\circ}$

Table 3 FishBAC's actuation torque estimates as a function of actuation input angle, angle of attack and freestream velocity. Torque estimates $\left[M_{x_{1}}, M_{x_{2}}\right]$ refer to to the actuators near the top and bottom force balances, respectively.

\begin{tabular}{|c|c|c|c|c|c|c|c|c|}
\hline \multirow{2}{*}{$\begin{array}{c}\text { Velocity } \\
(\mathrm{m} / \mathrm{s})\end{array}$} & \multirow{2}{*}{$\begin{array}{l}\text { AOA } \\
\text { (deg) }\end{array}$} & \multicolumn{7}{|c|}{ Torque $\left[\begin{array}{lll}\left.M_{x_{1}}, M_{x_{2}}\right] & (\mathrm{N} \mathrm{m})\end{array}\right.$} \\
\hline & & $\delta=+40^{\circ}$ & $\delta=+30^{\circ}$ & $\delta=+20^{\circ}$ & $\delta=+10^{\circ}$ & $\delta=0^{\circ}$ & $\delta=-10^{\circ}$ & $\delta=-20^{\circ}$ \\
\hline \multirow{2}{*}{30} & 0 & {$[0.63,0.77]$} & {$[0.54,0.52]$} & {$[0.28,0.28]$} & {$[0.18,0.20]$} & {$[0.20,0.12]$} & {$[-0.27,-0.22]$} & {$[-0.33,-0.38]$} \\
\hline & 5 & {$[0.66,0.75]$} & {$[0.53,0.54]$} & {$[0.30,0.33]$} & {$[0.17,0.19]$} & {$[0.20,0.12]$} & {$[-0.25,-0.23]$} & {$[-0.33,-0.37]$} \\
\hline 0 & 0 & {$[0.60,0.66]$} & {$[0.52,0.39]$} & {$[0.21,0.23]$} & {$[0.19,0.15]$} & {$[0.21,0.11]$} & {$[-0.24,-0.23]$} & {$[-0.33,-0.38]$} \\
\hline
\end{tabular}

Table 4 FishBAC's maximum deflections at three spanwise locations, and as a function of angle of attack and freestream velocity.

\begin{tabular}{|c|c|c|c|c|c|c|c|c|}
\hline & \multirow{2}{*}{$\begin{array}{c}\text { Velocity } \\
(\mathrm{m} / \mathrm{s})\end{array}$} & \multirow{2}{*}{$\begin{array}{l}\text { AOA } \\
\text { (deg) }\end{array}$} & \multicolumn{2}{|c|}{ Midspan } & \multicolumn{2}{|c|}{ Three-quarter-span } & \multicolumn{2}{|c|}{ Tendon } \\
\hline & & & $\delta=+40^{\circ}$ & $\delta=-30^{\circ}$ & $\delta=+40^{\circ}$ & $\delta=-30^{\circ}$ & $\delta=+40^{\circ}$ & $\delta=-30^{\circ}$ \\
\hline \multirow{3}{*}{$\begin{array}{l}\text { Displacement } \\
\qquad(\mathrm{mm})\end{array}$} & \multirow{2}{*}{30} & 0 & -5.60 & 3.47 & -10.8 & 9.45 & -13.3 & 10.7 \\
\hline & & 5 & $N / A$ & 3.58 & -6.34 & 5.71 & -10.9 & 7.12 \\
\hline & 0 & 0 & -10.8 & 8.16 & -17.7 & 14.3 & -19.1 & 17.9 \\
\hline
\end{tabular}


Table 5 FishBAC and Flap total power draw as a function of actuation angle input.

\begin{tabular}{ccccccccc}
\hline \multirow{2}{*}{ Configuration } & \multicolumn{7}{c}{ Power } & $(\mathrm{W})$ \\
\cline { 2 - 9 } & $\delta=+40^{\circ}$ & $\delta=+30^{\circ}$ & $\delta=+20^{\circ}$ & $\delta=+10^{\circ}$ & $\delta=0^{\circ}$ & $\delta=-10^{\circ}$ & $\delta=-20^{\circ}$ & $\delta=-30^{\circ}$ \\
\hline FishBAC & 20.37 & 13.49 & 8.67 & 5.37 & 4.60 & 6.95 & 10.03 & 17.64 \\
Flap & $\mathrm{N} / \mathrm{A}$ & 3.19 & 2.88 & 2.15 & 1.060 & 1.047 & 2.72 & $\mathrm{~N} / \mathrm{A}$ \\
\hline
\end{tabular}

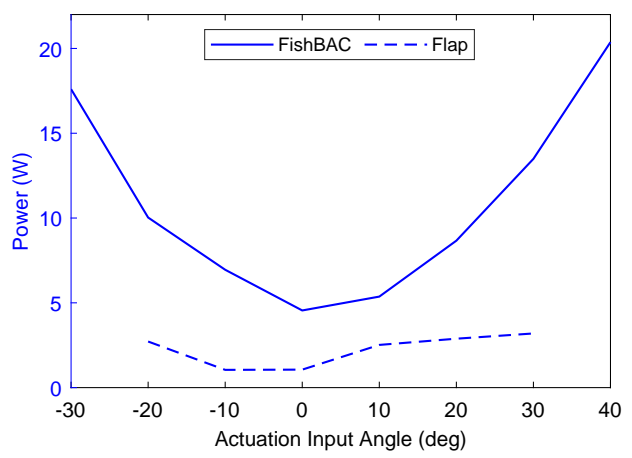

Fig. 21 FishBAC and Flap total power draw as a function of actuation angle input.

\section{Conclusions}

A wind tunnel study has been performed to investigate the aerodynamic performance of the FishBAC camber morphing device and to compare it against traditional trailing edge flaps. A 1-meter long NACA 23012 wind tunnel wing model was designed and manufactured for testing three different trailing edge configurations: baseline, FishBAC, and flapped. The wing was designed to span the height of Swansea University low-speed wind tunnel to create a quasi-two-dimensional flow condition. Force balance and wake rake survey data were used to quantify the aerodynamic performance of the different configurations at a range of angles of attack and camber deflections at a freestream velocity of $30 \mathrm{~m} / \mathrm{s}$. Additionally, optical aerodynamic and structural measurements were performed using PIV (aerodynamics) and videogauge (structural deflection), respectively. Results for the baseline airfoil have been compared to previous experimental results presented in the literature, as well as XFOIL numerical simulations. These are similar to previous literature and XFOIL estimates, with the main differences being attributable to different measuring techniques-force balance and wake rake versus airfoil pressure taps. Consideration of the experimental data leads to the following conclusions:

1) The FishBAC shows a significantly higher lift-to-drag-ratio than the hinged flap. This improvement is remarkable at moderate to high lift coefficients (i.e. $C_{L}>1$ ), where the improvement are at least of $50 \%$, and often over 200\%. For lower lift coefficients, where the most efficient configurations have very small camber deformations, the improvement is still at least $16 \%$, implying significant benefits from camber morphing even when its not being actively used. In general, the FishBAC presents a higher aerodynamic efficiency than the flap, for all angles 
of attack and lift coefficients.

2) Wake rake results show that, for a fixed angle of attack and similar actuation input, the flap wake thickness presents significant variation along the span, whereas the FishBAC's remains relatively constant. In terms of wake thickness, the flap shows two to four times thicker wake than the FishBAC.

3) PIV results show that the FishBAC's wake thickness is nearly constant with increasing deflection, having a stable value of $6 \%$ of chord length. Conversely, the wake thickness of the flap increases by $64 \%$ from its undeflected value, achieving a maximum wake thickness of $17.4 \%$ of chord length. Additionally, when comparing the two configurations, the flap has a wake that is two to three times the thickness of the FishBAC's wake. These results suggest that the flow is highly separated in the flap case, which is consistent with the drag increments observed in the pressure wake survey results of the hinged flap.

4) Aerodynamic loading was shown to decrease FishBAC's maximum deflections by between $42 \%$ and $60 \%$ at $\alpha=0^{\circ}$ and $\alpha=5^{\circ}$ respectively. It is expected that this reduction in deflection will increase with increasing angle of attack and freestream velocity, and highlights the importance of considering aerodynamic loads for actuation sizing purposes.

5) Flap's Reynolds stresses $\left(\overline{u^{\prime} u^{\prime}}\right.$ and $\left.\overline{v^{\prime} v^{\prime}}\right)$ and Turbulence Kinetic Energy are around an order of magnitude higher than the FishBAC's (at an actuation input angle of $\delta=+20^{\circ}$ ). Results suggest the existence of bluff body like vortex shedding when the flap is deflected, while the wake of the FishBAC is similar to that of attached flow over the airfoil.

6) The FishBAC has significantly higher actuation power requirements than the flap, requiring $300 \%$ more power on average. Additionally, these power requirements grow significantly with increasing FishBAC deflection.

In summary, these results show the great promise that the FishBAC has in terms of aerodynamic efficiency and shape optimization. Future work will focus on 3D aerodynamic tests, 3D PIV measurements and additional displacement measurements for fluid-structure interaction validation purposes.

\section{Acknowledgments}

This work was supported by the Engineering and Physical Sciences Research Council through the EPSRC center for Doctoral Training in Advanced Composites for Innovation and Science [grant number EP/L016028/1]. Furthermore, this project has received funding from the European Union's Horizon 2020 research and innovation program as part of the SABRE: Shape Adaptive Blades for Rotorcraft Efficiency project (grant agreement No. 723491). Lastly, the authors would like to acknowledge the support provided by Dr Chen Wang and Prof. Michael Friswell (College of Engineering at Swansea University) during the manufacturing process of the FishBAC wind tunnel wing model and wind tunnel tests. 


\section{Data Access Statement}

All underlying raw data used in this study are available for download from the Research Data Repository of University of Bristol, data.bris, at: https://data.bris.ac.uk/data/dataset/1w3w5nw71enrx22zppkyd650fe

\section{References}

[1] Greff, E., "The development and design integration of a variable camber wing for long/medium range aircraft," The Aeronautical Journal, Vol. 94, No. 939, 1990, pp. 301-312.

[2] Barbarino, S., Bilgen, O., Ajaj, R. M., Friswell, M. I., and Inman, D. J., “A Review of Morphing Aircraft,” Journal of Intelligent Material Systems and Structures, Vol. 22, No. 9, 2011, pp. 823-877. doi:10.1177/1045389X11414084.

[3] Beaverstock, C., Woods, B., Fincham, J., and Friswell, M., "Performance Comparison between Optimised Camber and Span for a Morphing Wing," Aerospace, Vol. 2, No. 3, 2015, pp. 524-554. doi:10.3390/aerospace2030524, URL http: //wWw.mdpi.com/2226-4310/2/3/524/

[4] Parker, H., “The Parker Variable Camber,” Tech. Rep. 77, National Advisory Committee for Aeronautics, Washington, DC, 1920.

[5] Hogan, H. J., "Variable Camber Airfoil," U.S. Patent 1 ,868,748, 1932.

[6] Chilton, R., "Variable Area-and-Camber Wing," U.S. Patent 2,222,935, 1940.

[7] Kota, S., Hetrick, J. A., Osborn, R., Paul, D., Pendleton, E., Flick, P., and Tilmann, C., "Design and application of compliant mechanisms for morphing aircraft structures," Proc. SPIE, Vol. 5054, No. November, 2003, pp. 24-33. doi:10.1117/12.483869, URL http://dx.doi .org/10.1117/12.483869.

[8] Bilgen, O., Friswell, M. I., Kochersberger, K. B., and Inman, D. J., "Surface Actuated Variable-Camber and Variable-Twist Morphing Wings Using Piezocomposites," Structures, Structural Dynamics and Materials Conference, Vol. 19, No. April, 2011, pp. 1-13. doi:10.2514/6.2011-2072.

[9] Barbarino, S., Pecora, R., Lecce, L., Concilio, A., Ameduri, S., and Calvi, E., "A novel SMA-based concept for airfoil structural morphing," Journal of Materials Engineering and Performance, Vol. 18, No. 5-6, 2009, pp. 696-705. doi: 10.1007/s11665-009-9356-3.

[10] Sofla, A., Meguid, S., Tan, K., and Yeo, W., "Shape morphing of aircraft wing: Status and challenges," Materials \& Design, Vol. 31, No. 3, 2010, pp. 1284-1292. doi:10.1016/j.matdes.2009.09.011, URL http://linkinghub.elsevier.com/ retrieve/pii/S0261306909004968

[11] Diaconu, C. G., Weaver, P. M., and Mattioni, F., "Concepts for morphing airfoil sections using bi-stable laminated composite structures," Thin-Walled Structures, Vol. 46, No. 6, 2008, pp. 689-701. doi:10.1016/j.tws.2007.11.002.

[12] Daynes, S., Nall, S., Weaver, P., Potter, K., Margaris, P., and Mellor, P., "Bistable Composite Flap for an Airfoil," Journal of Aircraft, Vol. 47, No. 1, 2010, pp. 334-338. doi:10.2514/6.2009-2103, URL http://arc.aiaa.org/doi/abs/10.2514/6. 2009-2103.

[13] Larson, R. R., "Flight Control System Development and Flight Test Experience With the F-111 Mission Adaptive Wing Aircraft,” Tech. rep., NASA Ames Research Center, Edwards, California, 1986.

[14] Kudva, J. N., "Overview of the DARPA Smart Wing Project," Journal of Intelligent Materials Systems and Structures, Vol. 15, No. 4, 2004, pp. 261-267. doi:10.1177/1045389X04042796.

[15] Campanile, L. F., and Sachau, D., "Belt-rib concept: a structronic approach to variable camber," Journal of Intelligent Material Systems and Structures, Vol. 11, No. 3, 2000, pp. 215-224. doi:10.1106/6H4B-HBW3-VDJ8-NB8A.

[16] Woods, B. K. S., and Friswell, M. I., "Preliminary Investigation of a Fishbone Active Camber Concept," ASME Conference on Smart Materials, Adaptive Structures and Intelligent Systems, 2012. doi:10.1017/CBO9781107415324.004. 
[17] Szodruch, J., "The influence of camber variation on the aerodynamics of civil transport aircraft," 23rd Aerospace Sciences Meeting, 1985. doi:10.2514/6.1985-353, URL http://arc.aiaa.org/doi/10.2514/6.1985-353.

[18] Szodruch, J., and Hilbig, R., "Variable wing camber for transport aircraft," Progress in Aerospace Sciences, Vol. 25, No. 3, 1988, pp. 297-328. doi:10.1016/0376-0421(88)90003-6.

[19] Daynes, S., and Weaver, P. M., "Morphing Blade Fluid-Structure Interaction," 53rd AIAA/ASME/ASCE/AHS/ASC Structures, Structural Dynamics and Materials Conference, Honolulu, Hawaii, 2012. doi:10.2514/6.2012-1667.

[20] Bilgen, O., Kochersberger, K., Diggs, E., Kurdila, A., and Inman, D., "Morphing Wing Micro-Air-Vehicles via Macro-FiberComposite Actuators," 48th AIAA/ASME/ASCE/AHS/ASC Structures, Structural Dynamics, and Materials Conference, 2007, pp. 1-16. doi:10.2514/6.2007-1785, URL http://arc.aiaa.org/doi/10.2514/6.2007-1785

[21] Ai, Q., Kamliya Jawahar, H., and Azarpeyvand, M., "Experimental investigation of aerodynamic performance of airfoils fitted with morphing trailing edges," 54th AIAA Aerospace Sciences Meeting, 2016. doi:10.2514/6.2016-1563, URL http://arc.aiaa.org/doi/10.2514/6.2016-1563

[22] Yokozeki, T., Sugiura, A., and Hirano, Y., "Development and Wind Tunnel Test of Variable Camber Morphing Wing," 22nd AIAA/ASME/AHS Adaptive Structures Conference, 2014, pp. 6-13. doi:10.2514/6.2014-1261, URL/http://arc.aiaa.org/ doi/10.2514/6.2014-1261

[23] Woods, B. K. S., Bilgen, O., and Friswell, M. I., "Wind tunnel testing of the fish bone active camber morphing concept," Journal of Intelligent Material Systems and Structures, Vol. 25, No. 7, 2014, pp. 772-785. doi:10.1177/1045389X14521700.

[24] Woods, B. K., Fincham, J., and Friswell, M. I., “Aerodynamic Modelling of the Fish Bone Active Camber Morphin,” RAeS Applied Aerodynamics Conference, Bristol, UK, 2014, pp. 1-12.

[25] AEROTECH, A., “Operational Manual for Swansea University Low Speed Wind Tunnel,”, 2017.

[26] Imetrum, “3D Measurement Head Range,”, 2018.

[27] Drela, M., "XFOIL: An Analysis and Design System for Low Reynolds Number Airfoils," Lecture Notes in Engineering, edited by T. Mueller, Springer, Berlin, Heidelberg, 1989, 54 ${ }^{\text {th }}$ ed., pp. 1-12. doi:10.1007/978-3-642-84010-4\{\\}1.

[28] Barlow, J., Rae, W., and Pope, A., Low-Speed Wind Tunnel Testing, $3^{\text {rd }}$ ed., Wiley, 1999.

[29] Rivero, A. E., Fournier, S., and Cooper, J. E., "Wind Tunnel Comparison of Flapped and FishBAC Camber Variation for Lift Control," AIAA SciTech 2020 Forum, American Institute of Aeronautics and Astronautics, Orlando, FL, 2020, pp. 1-18. doi:10.2514/6.2020-1300.

[30] Rivero, A. E., Weaver, P. M., Cooper, J. E., and Woods, B. K., "Structural modeling of compliance-based morphing structures under transverse shear loading," AIAA Journal (not yet published), 2020.

[31] Rivero, A. E., Fournier, S., Weaver, P. M., Cooper, J. E., and Woods, B. K. S., "Manufacturing and characterisation of a composite FishBAC morphing wind tunnel model," ICAST 2018: 29th International Conference on Adaptive Structures and Technologies, Seoul, Republic of Korea, 2018, pp. 1-14.

[32] Rivero, A. E., Weaver, P., and Woods, B. K., "Structural Modelling of Compliance-Based Morphing Structures under Transverse Shear Loading," AIAA SciTech 2019 Forum, American Institute of Aeronautics and Astronautics, San Diego, CA, 2019. doi:10.2514/6.2019-0229, URL https://arc.aiaa.org/doi/10.2514/6.2019-0229.

[33] Ashenden, R., Lindberg, W., and Marwitz, J. D., "Two-dimensional NACA 23012 airfoil performance degradation by super cooled cloud, drizzle, and rain drop icing," 34th Aerospace Sciences Meeting and Exhibition, 1996. doi:10.2514/6.1996-870.

[34] Pouryoussefi, S. G., Mirzaei, M., Nazemi, M. M., Fouladi, M., and Doostmahmoudi, A., "Experimental study of ice accretion effects on aerodynamic performance of an NACA 23012 airfoil," Chinese Journal of Aeronautics, Vol. 29, No. 3, 2016 , pp. 585-595. doi:10.1016/j.cja.2016.03.002, URL http://dx.doi.org/10.1016/j.cja.2016.03.002

[35] Leishman, J. G., "Dynamic stall experiments on the NACA 23012 aerofoil," Experiments in Fluids, Vol. 9, 1990, pp. 49-58. doi:10.1007/s003480050014. 
[36] Jacobs, E. N., and Sherman, A., "Airfoil Section Characteristics as Affected by Variations of Reynolds Number," Tech. rep., National Advisory Committee for Aeronautics, Langley Field, Virginia, 1939.

[37] Woods, B. K. S., and Friswell, M. I., "Fluid-Structure Interaction Analysis of the Fish Bone Active Camber Mechanism," 54th AIAA/ASME/ASCE/AHS/ASC Structures, Structural Dynamics, and Materials Conference, Boston, Massachusetts, 2013, pp. $1-15$.

[38] Huntley, S. J., Allen, C. B., and Woods, B. K., "Computational Analysis of the Aerodynamics of Camber Morphing," AIAA Aviation Forum, Dallas, Texas, 2019, pp. 1-20. doi:10.2514/6.2019-2914.

[39] Brennen, C. E., An Internet Book on Fluid Dynamics Reynolds Stresses, Dankat Publishing, 2006. URL http://brennen. caltech.edu/fluidbook/basicfluiddynamics/turbulence/reynoldsstresses.pdf

[40] Manolesos, M., and Voutsinas, S. G., "Experimental study of drag-reduction devices on a flatback airfoil," AIAA Journal, Vol. 54, No. 11, 2016, pp. 3382-3396. doi:10.2514/1.J054901.

[41] Savli, M., “Turbulence kinetic energy - TKE,” Faculty of Mathematics and Physics, University of Ljubljana, 2012, p. 14. URL http://mafija.fmf.uni-lj.si/seminar/files/2011_2012/MaticSavli_2.pdf 